\title{
TESEU, O LABIRINTO E SEU NOME: COMO HOMI K. BHABHA PODERIA NOS AJUDAR A COMPREENDER UMA PASSAGEM DE MOI, TITUBA SORCIÈRE..., DE MARYSE CONDÉ?
}

Jonata Oliveira ${ }^{25}$

Alcione Alves ${ }^{26}$

RESUMO: Propõe-se uma interpretação da obra de Maryse Condé, intitulada Eu, Tituba, feiticeira...negra de Salem (1997); o romance é inspirado na história de Tituba, sendo esta a única negra entre as mulheres condenadas no trágico incidente, ocorrido há três séculos, na cidade de Salem, promovido pela intolerância religiosa no interior de uma sociedade influenciada por normas puritanas. Busca-se compreender a ressignificação do termo feiticeira, por parte de Tituba, em um estudo fundamentado, sobretudo, nas noções de hibridismo e fronteira trazidas por Homi K. Bhabha em O local da cultura (2013). As discussões e produções científicas atinentes a este estudo têm sido elaboradas no âmbito do Projeto de Pesquisa Teseu, o labirinto e seu nome, vigente na Universidade Federal do Piauí.

Palavras-chave: Maryse Condé: romance; construções identitárias negras americanas; Homi K. Bhabha: teoria; hibridismo; fronteira.

RESÚMEN: Proponemos en este artículo una interpretación del romance de Maryse Condé Eu, Tituba, feiticeira...negra de Salem (1997), inspirado en la historia de Tituba, la única negra entre las mujeres condenadas hace tres siglos en la ciudad de Salem; su condena se la ha interpretado en un cuadro de intolerancia religiosa en una sociedad de normas puritanas. Busca-se en ese texto comprender la re-significación del término feiticeira, por Tituba, apoyándonos sobretodo en las nociones de hibridismo y frontera desde Homi K. Bhabha en O local da cultura (2013).

\footnotetext{
25 Mestre em Letras pela Universidade Federal do Piaui-UFPI

${ }^{26}$ Doutor em Letras pela Universidade Federal do Rio Grande do Sul-UFRGS. Professor Adjunto da Universidade Federal do Piaui.
} 
Las discusiones y producciones científicas referentes a esta investigación han sido desarrolladas bajo el Projecto de Investigación Teseo, el laberinto y su nombre, ubicado en la Universidade Federal do Piauí.

Palabras-clave: Maryse Condé: romance; construcciones identitarias negras americanas; Homi K. Bhabha: teoría; hibridismo; frontera.

A las(los) discentes de los cursos de
postgrado PPGEL006 y
PPGEL036, dictados el el primer
semestre de 2015, bajo el
Programa de Postgrado en Letras
de la Universidade Federal do

Piauí

No II Encontro Internacional Fronteiras e Identidades, realizado na Universidade Federal de Pelotas, apresentamos uma primeira comunicação visando a discutir a noção de hibridismo, conforme a formulação de Homi K. Bhabha em sua obra O local da cultura (2013), evidenciando sua importância para pensar as estratégias de resistência de sujeitos em-subalternidade, escravizados, de modo a interpretar suas construções identitárias na obra Moi Tituba sorcière..., de Maryse Condé; à luz do conceito de Bhabha, a hipótese em questão propunha tais construções identitárias enquanto processos de ressignificação, assim como de produção de novos signos, nos espaços intervalares entre fronteiras.

Em uma abordagem posterior ${ }^{27}$ ao romance Moi, Tituba, sorcière... $^{28}$, de Maryse Condé (1997), buscou-se elaborar um estudo sobre as estratégias de apropriações, vivências e sobrevivências de uma cultura particular frente aos processos de dominação e exclusão, tendo como aporte teórico o hibridismo ${ }^{29}$ cultural na formulação de Bhabha $^{30}$.

\footnotetext{
${ }^{27}$ Uma primeira versão a este artigo, posterior ao já mencionado Encontro na Universidade Federal de Pelotas, fora publicada, como capitulo de livro, intitulado "Identidade, ressignificação e resistência" (OLIVEIRA, ALVES, 2015, p. 71-81). Dos avanços a estas duas etapas anteriores de pesquisa, resulta o presente artigo.

${ }^{28}$ Tradução para o português a cargo de Lilian Corrêa, 1997.

${ }^{29}$ Importante salientar que termo hibridismo dentro dos estudos pós-coloniais é emprestado da biologia. Sua primeira definição, presente no Dicionário Houaiss da Lingua Portuguesa,
} 
Teseu, o labirinto e seu nome: como Homi K. Bhabha poderia nos ajudar a compreender uma passagem de Moi, Tituba Sorcière..., de Maryse Condé?| 93

Comparado a outras formulações como, por exemplo, em Néstor García Canclini $^{31}$, torna-se polêmico quando "traz para seus estudos interpretações de um hibridismo intencional assumido dentro de um contexto na qual sobrevivem duas verdades contraditórias, a do colonizador e a do colonizado" (OLIVEIRA, ALVES, 2015); destacar esses valores conflitantes em uma instância (pós-)colonial significa apontar a intencionalidade do discurso híbrido do colonizado frente ao discurso do poder.

assim estabelece: "animal ger. estéril, formado pelo cruzamento de progenitores de espécies diferentes; bastardo (e.g. burro e mula)" (Apud HANCIAU, 2012, p.165). A fim de pensar as novas culturas que emergiram das zonas de intensos fluxos, a apropriação deste termo e parte do seu conceito, inicialmente desenvolvido pela biologia no século XIX, vem sendo amplamente utilizado em vários campos do conhecimento intelectual. Outro termo que também caracterizaria esse processo de mistura, "principalmente associado à mistura de raças, no sentido, portanto, de miscigenação” (CANCLINI apud BERND, 2004, p. 100) seria a mestiçagem.

${ }^{30}$ Para um conceito de hibridismo, cabe considerar, ao menos, três teóricos. No campo dos Estudos Culturais, Stuart Hall (1997) argumenta que dos processos de deslocamentos, como a diáspora, decorreriam identidades hibridas ainda que (e sem contradição de termos), em um momento em que a globalização, "novos aspirantes ao status de 'nação" (p. 102) busquem reconstruir identidades mais próximas a bases [tomadas por nós como] essencialistas; nas bases reivindicadas por Hall, tornar-se-ia impossivel preservar as identidades culturais monoliticas uma vez que as culturas estão cada vez expostas a influências exógenas; nerste sentido, pessoas em condições de deslocamento tenderiam a negociar com as novas culturas em contato. De sua parte, segundo Néstor Garcia Canclini, as diversas mesclas interculturais referem-se à hibridização cultural; nas palavras de Marli Fantini (2004), para Canclini esse processo se daria a partir da dinamicidade de manifestações das culturas populares; assim, "esse hibridismo, desencadeador de combinatórias e sinteses imprevistas, caracterizou o século XX em diferentes campos, possibilitando desdobramentos, produtividade e poder criativo inovadores das mesclas interculturais já existentes na América Latina" (Idem, p. 168). Por sua vez, Mikhail Bakhtin é considerado o precursor da discussão da ideia de híbrido quando, em seus estudos, exprime a concepção dialógica da linguagem: ao propor que a lingua possui propriedade dialógica, Bakhtin aponta que "o enunciador, para constituir um discurso, leva em conta o discurso de outrem, que está presente no seu” (FIORIM, 2004, p. 38); logo, partindo desse pressuposto, a linguagem é heterogênea. Em um horizonte de critica pós-colonial, tomamos em conta que Bhabha desenvolvera seu próprio conceito de hibridismo a partir de Bakhtin.

${ }^{31}$ Segundo Canclini, as diversas mesclas interculturais referem-se à hibridização cultural. Para o teórico mexicano, nas palavras de Marli Fantini (2004), esse processo é gerado a partir da dinamicidade de manifestações das culturas populares e o caldeamento destas com o culto. Assim, Fantini acrescenta que "esse hibridismo, desencadeador de combinatórias e sinteses imprevistas, caracterizou o século XX em diferentes campos, possibilitando desdobramentos, produtividade e poder criativo inovadores das mesclas interculturais já existentes na América Latina" (p. 168). 
Partindo das discussões e avanços decorrentes, com vistas a avançar na compreensão da obra de Condé, ora propomos, retomando as formulações de Bhabha acerca da fronteira, examinar brevemente algumas de suas possibilidades e limites a uma compreensão das literaturas negras caribenhas contemporâneas, mediante exame da protagonista Tituba, em seus processos de construções identitárias. Como hipótese a este trabalho especulativo, espera-se o estabelecimento de um diálogo, propositivo, entre os limites próprios aos conceitos de hibridismo e fronteira, em Bhabha, e uma ideia de nascimento e morte nas águas do Atlântico, tomadas desde este lugar como fronteira entre Áfricas e Américas, entre vida e morte ${ }^{32}$.

Não significa dizer que o hibridismo, em tais termos, se trate de um antagonismo aberto mas, segundo Stelamaris Coser, de um conceito vinculado à "estratégia ou discurso de negociação em condições de desigualdade e antagonismo político" (COSER, 2012, p. 173-174) e, dentro dessa compreensão, um espaço de subalternidade, de modo a tomar o hibridismo como "agência contestadora" que "representa aquele 'desvio' ambivalente do sujeito discriminado em direção ao objeto aterrorizante, exorbitante, da classificação paranoica - um questionamento perturbador das imagens e presenças da autoridade" (BHABHA, 2013, p. 188).

Bhabha propõe que o hibridismo, problematizando a representação do sujeito subalterno, possibilita a reversão à recusa do Outro por meio de uma camuflagem, discursiva, dentro do discurso dominante, de tal modo que a apropriação consciente desse discurso permitiria compreender a resistência do sujeito discriminado a partir do questionamento, dissimulado, da autoridade: a partir desse jogo dialético entre duas identidades assimétricas, se pode observar a proposta de Bhabha sobre a noção de entre-lugares (também chamado por ele de espaços intersticiais). Os entre-lugares corresponderiam aos "momentos ou processos que são produzidos na articulação de diferenças culturais" e "dão início a novos signos de identidades e postos inovadores de colaboração e contestação":

\footnotetext{
${ }^{32}$ Este estudo se constrói como parte da dissertação de mestrado em andamento, intitulada "A resistência ao olho do poder: hibridismo e desvio no romance Eu, Tituba, Feiticeira...Negra de Salem", atualmente elaborada por Jônata Ribeiro de Oliveira, no âmbito do Projeto de Pesquisa Teseu, o labirinto e seu nome, vigente na Universidade Federal do Piauí.
} 
Teseu, o labirinto e seu nome: como Homi K. Bhabha poderia nos ajudar a compreender uma passagem de Moi, Tituba Sorcière..., de Maryse Condé?| 95

O que é teoricamente inovador e politicamente crucial é a necessidade de passar além das narrativas das subejtividades originárias e iniciais e de focalizar aqueles momentos ou processos que são produzidos na articulação das diferenças culturais. Esses "entre-lugares" fornecem o terreno para a elaboração de estratégias de subjetivação - singular ou coletiva - que dão início a novos signos de identidade e postos inovadores de colaboração e contestação, no ato de definir a própria idéia de sociedade (BHABHA, 2013, p. 20).

Ante a importância dos planetamentos teóricos na introdução de O local da cultura à formação vigente de nosso campo, convém assinalar, nesta apresentação dos entre-lugares, o papel delegado ao verbo focalizar que, antes de definir uma suposta natureza própria a determinadas identidades, reivindica um eixo politico em nosso trabalho investigativo: em outros termos, o verbo focalizar, auxiliado pelo verbo passar, nos convida a um interesse de investigação de nosso objeto literário, precisamente, sobre "aqueles momentos ou processos que são produzidos na articulação das diferenças culturais”, mas de tal modo que os entrelugares se apresentem como categoria de análise antes de naturalização de identidades em-subalternidade ou, dito de outro modo, naturalização das identidades de nossos Outros. Em tal esquema, constataríamos Tituba e John Índio enquanto personagens cujo entre-lugar lhes seria, natural[izada]mente, sua única alternativa, cenário que conduziria nossa leitura do conceito de Bhabha a uma aporia: tendo em vista que este propicia aos sujeitos "o terreno para a elaboração de estratégias de subjetivação - singular ou coletiva - que dão início a novos signos de identidade e postos inovadores de colaboração e contestação", como perceber interpretações científicas que, a contrapelo do conceito reivindicado, estipulariam (talvez, igualmente, a contrapelo) o entre- como única alternativa possivel a determinados sujeitos, não por coincidência aqueles que tomamos como natural[izada]mente nossos subalternos, nossos Outros?

É na emergência dos interstícios - a sobreposição e os deslocamentos dos domínios da diferença - que as experiências intersubjetivas e coletivas de nação [nationness], 
o interesse comunitário ou o valor cultural são negociados. De que modo se formam sujeitos nos "entre-lugares", nos excedentes da soma das "partes" da diferença (geralmente expressas como raça/classe/gênero etc.)? (Idem, p. 20)

Isso nos levaria a interpretar o conselho de John Índio a Tituba acerca da religião vigente em Salém como uma negociação que busca a constituição dele e de Tituba como sujeitos em um ambiente hostil de escravização, antes de tomar quaisquer formas de religiosidades de matriz africana imediata e natural[izada]mente como entre-lugares de religosidade dada sua natureza enquanto “'partes' da diferença (geralmente expressas como raça/classe/gênero etc.)". Igualmente, a divergência de estratégias adotada entre os dois personagens, no tocante a este problema pontual, nos oferece um indício para por em questão nossos limites para interpretar, quiçá para respeitar a prerrogativa de "elaboração de estratégias de subjetivação - singular ou coletiva" negadas aos sujeitos que investigamos ${ }^{33}$ quando os tomamos, homogênea e natural[izada]mente como Outros, habitantes de uma nação chamada Entre-lugar, localizada no continente Diáspora. Tomando os termos da tradução de Bhabha, a estes sujeitos nationess, se trata de uma negociação, não de uma dívida natural[izada] dada sua condição como " "partes' da diferença (geralmente expressas como raça/classe/gênero etc.)”.

Nesse caso, Bhabha não se refere ao hibridismo como um terceiro termo que põe em relação duas culturas em conflito, mas o considera como "uma problemática de representação e de individuação colonial que reverte os efeitos de recusa colonialista” (idem, p. 188).

Ora, o espaço da fronteira, do limes, traz em si uma terceira dimensão, um plano em descompasso que permite apreender o território a partir de um ponto de vista tanto externo quanto interno. A fronteira que procurarei mostrar retomando a definição de limes como caminho entre dois territórios e não pertencendo nem a um nem a outro mas aos dois, abre a perspectiva de um terceiro olhar, nem perdido na singularidade do lugar, na cor local, no genius

\footnotetext{
${ }^{33}$ Neste caso, a uma mulher de origem ashanti, mas já nascida fora do continente de sua familia, em regime de escravização em uma comunidade puritana no norte da América.
} 
Teseu, o labirinto e seu nome: como Homi K. Bhabha poderia nos ajudar a compreender uma passagem de Moi, Tituba Sorcière..., de Maryse Condé?| 97

loci, nem perdido nas brumas da abstração universalizante (LEENHARDT, 2002, p. 30)

Em nossa observação ao campo semântico em torno do hibridismo e da fronteira como apoios para interpretar a obra de Condé, assim como a boa parte do campo semântico do qual nos servimos para pensar as construções identitárias americanas em nosso campo, talvez não se busque resolvê-las mediante a busca por um terceiro espaço, simultaneamente tributário de ambos os espaços em conflito, "não pertencendo nem a um nem a outro mas os dois"; ainda que se aprecie, para fins de análise, a potencialidade dem um conceito de fronteira para evidenciar, incidir sobre o conflito (e, especificamente, o conflito como problema atinente a uma ciência dedicada ao objeto literário), mostra-se fundamental abrir ressalvas a um execício que apresente, como consequência de uma análise deste conflito, e de modo naturalizado, a necessidade "de um terceiro olhar, nem perdido na singularidade do lugar, na cor local, no genius loci, nem perdido nas brumas da abstração universalizante". Por um momento desconsiderando nossas bases pósmodernas de formação acadêmica, corremos o risco de, ao propor o terceiro-olhar não como uma chave interpretativa atualmente vigente na comunidade científica mas como uma poética inerente [porque, uma vez mais: naturalizada] às literaturas em-subalternidade por nós investigadas, talvez apresentar, ao fim e ao cabo, uma solução muito mais almejada por nós, sujeitos-em-pesquisa, do que pelos sujeitos [e suas construções identitárias] que investigamos.

Do que decorre, nesta interpretação de Eu, Tituba, feiticeira...negra de Salém, examinar como se dariam as negociações da protagonista na emergência dos interstícios, atentando à ressalva, em Bhabha, de que tais negociações podem ocorrer tanto de maneira 'agonística', mas também conflituosa e 'antagonística', a despeito de nossas[eventuais] tendências a sínteses totalizantes, harmonizadoras da diferença como suplemento. A partir do jogo entre duas identidades assimétricas, se poderia observar uma dinâmica da transformação dos símbolos, nos espaços intermediários das fronteiras culturais, nos quais se daria a representação do sujeito subalterno: a partir de Bhabha, se nos torna possível perceber as identidades nos intervalos das fronteiras (interstícios), nos lugares onde ocorrem os "momentos ou processos que são produzidos na articulação de diferenças culturais" e "dão início a novos signos de identidades e 
postos inovadores de colaboração e contestação" (BHABHA, 2013, p. 20). Essa produção resultaria dos efeitos discriminatórios gerados pelo colonialismo, favorecendo o surgimento de um terceiro termo, sucessivo, híbrido, que desafia as fronteiras hegemônicas e essencialistas do discurso do poder.

Supondo a memória de Tituba um espaço intersticial, se pode constatar a resistência da personagem ao regime de reconhecimento da autoridade mediante sua recusa ao significado, exógeno, do termo feiticeira, consequência das implicações discriminatórias do poder colonial, no qual "o semântico parece prevalecer sobre o sintático, o significao sobre o significante" (BHABHA, 2013, p. 181).

- Ai! O que está fazendo, feiticeira?/ Falava assim de brincadeira. De todo modo, fiquei espantada./ O que é uma feiticeira?/ Percebi que, em sua boca, a palavra estava manchada de desonra. Como isso? Como? A faculdade de se comunicar com os invisiveis, manter uma ligação constante com os desaparecidos, de cuidar, de curar, não é uma graça superior da natureza, que inspira respeito, admiração e gratidão? Em consequência, a feiticeira, se se quer dar esse nome àquela que possui essa graça, não deveria ser tratada com desvelos e reverenciada em lugar de temida? (CONDÉ, 1997, p. 28, 29) ${ }^{34}$

Em vista disso, os estranhamentos e as indagações do termo feiticeira pela protagonista, antes significado pelo outro, tende a um processo de mutação, compreendendo que seu saldo lograria em outro conceito, diferente do imposto pelo colonizador. Tal recusa, acionada por Tituba, "confere novas implicações estratégicas de subversão que fazem o olhar do discriminado voltar-se para o olho do poder [...]" (BHABHA, p. 186).

\footnotetext{
34 Texto original: “- Aie! Qu'est-ce que tu fais là, sorcière?/ Il parlait ainsi par jeu./ Néanmoins, cela m'assombrit./ Qu'est-ce qu'une sorcière?/ Je m'apercevais que dans as bouche, le mot était entaché d'opprobre. Comment cela? Comment? La faculté de communiquer avec les invisibles, de garder un lien constant avec les disparus, de soigner, de guérir n'est-elle pas une grâce supérieure de nature à inspirer respect, admiration et gratitude? En conséquence, la socière, si on veut nonmer ainsi celle qui possède cette grâce, ne devrait-elle pas être choyée et révérée au lieu d'être crainte?" (CONDÉ, 1986, p.33, 34).
} 
Teseu, o labirinto e seu nome: como Homi K. Bhabha poderia nos ajudar a compreender uma passagem de Moi, Tituba Sorcière..., de Maryse Condé?| 99

As apropriações e as significações aparecem, estrategicamente, desde o título do romance, na qual outros vocábulos do título também mostram-se importantes e suplementares a estas proposições, qual seja o pronome Eu e seu respectivo no francês, Moi, para designar o sujeito enunciante, dotado de auto-representatividade; adjunto, e referindo-se a este primeiro termo, segue-se Tituba; logo, há um sujeito que fala e possui um nome (OLIVEIRA, ALVES, 2015), enunciando uma história que, antes registrada por uma historiografia oficial insuficiente, agora passa a ser enunciada desde a própria personagem, desde um lugar negro feminino ${ }^{35}$.

Eu, Tituba, feiticeira...negra de Salem, originalmente publicado em 1986, parte da história de Tituba, única mulher negra entre as condenadas no incidente ocorrido em Salem ${ }^{36}$, no final do século XVII; importante à diegese salientar que tal condenação tem, como contexto, um cenário de intolerância religiosa no interior de uma sociedade de normas puritanas. $\mathrm{O}$ romance trata da vida de Tituba, filha de uma negra escravizada, numa narrativa que situa, em primeiro plano, o negro escravizado, em especial a mulher negra, nos últimos anos do século $\mathrm{XVII}^{37}$. A promoção de um discurso dito marginal, representado por uma consciência coletiva posta à margem pelo discurso universal ${ }^{38}$, se dá a

35 O que aproxima o romance de Maryse Condé de las Negras (2012), de Yolanda Arroyo Pizarro, e de Humus (2007), de Fabienne Kanor, todas as três obras comportando uma interpretação que as tome como enunciações desde um lugar negro feminino americano ou, melhro dito, como escrevivências (EVARISTO, 2009) negras femininas americanas. Ademais da dimensão ficcional, este mesmo problema se mostra argumentado, também, mediante o ensaio negro feminino americano, caso tomemos em conta os ensaios "Sans titre" (KANOR, 2007) e "Hablar de las Ancestras: hacia una nueva literatura insurgente de la afrodescendencia" (ARROYO PIZARRO, 2011).

${ }^{36} \mathrm{O}$ incidente de Salem é um fato verídico que foi desencadeado pela intolerância religiosa a partir das práticas de "feitiçarias" de Tituba.

${ }^{37} \mathrm{O}$ que, conforme Gayatri Chakravorty Spivak, parece ser mais problemática pois, no contexto da subalternidade, "se você é pobre, negra e mulher está envolvida de três maneiras" (2010, p. 85).

${ }^{38}$ Para Édouard Glissant, o discurso do Ser assume uma postura sublimadora do Outro, em sua quase totalidade; o Ser tende à transcendência universal e "se eleva na êxtase dos individuos". O Diverso, estabelecido pela Relação, reage diante do Ser, desde uma perspectiva coletiva, mostrando sua permanência a favor da totalidade dos povos e da comunidade. Em Glissant, esses termos buscam compreender uma tendência sublimadora de culturas hegemônicas da globalização sobre culturas particulares. Assim, a Relação é posta como um projeto de igualdade pois "lo Diverso no es caótico ni lo estério, significa el esfuerzo del espiritu humano hacia uma relación universal, sin transcendência universalista. 
partir da enunciação do sujeito, seja ele escritor de obra literária ou personagem de uma determinada história, ressignificação fundamental a sua construção identitária.

Tituba assume a responsabilidade de contar sua condição de sujeito escravizado; o caráter central de sua personagem permite a ela, simultaneamente narradora e protagonista, reivindicar um discurso tomado para si, no seu modo de narrar, com o direito de relatar as punições à qual foram submetidas ela mesma, sua mãe e outros negros escravizados.

Apesar da proposta teórica de que as negociações culturais se deem em espaços intersticiais entre fronteiras, considera-se que esse espaço intervalar, ao mesmo tempo em que abre possibilidades de pensar a afiliação e confluência entre as diversas culturas, também se constitui em espaço de interrogação sobre a representação. Nubia Hanciau (2012, p. 133) afirma que as fronteiras aparece um tanto complexas uma vez que abarcam tanto o domínio real (de territorialidade) quanto imaginário, ambas as vias abrindo possíbilidades de pensá-las politicamente: "a fronteira constitui-se em encerramento de um espaço, (...) avança para os domínios da construção simbólica de pertencimento denominada identidade e que corresponde a um marco de referência imaginária, definido pela diferença e alteridade na relação com o outro" (idem, p. 133). A fronteira traz, nesse sentido, um caráter de ambivalência em situações díspares, representadas pelos protagonistas de um dado contexto dentro do espaço colonial, na qual quem coloniza (na diegese, tanto a dimensão macro de uma comunidade puritana quanto a dimensão micro dos casais Parris e Endicott como proprietários da escravizadas(os)) exerce sua autoridade ante sujeitos colonizados que, sob domínio, indagam de modo a confrontar o caráter unitário e universalista no discurso do poder.

Eis a complexidade das negociações a que Bhabha se refere visto que o "direito" de se expressar a partir da margem não depende da "persistência da tradição", mas "é alimentado pelo poder da tradição de se reinscrever através das condições de contingência e contraditoriedade que presidem sobre as vidas dos que 'estão' na minoria ${ }^{39 "}$ (p. 21): aquí se abre

Lo Diverso necessita la presencia de los pueblos, ya no como objeto que debe ser sublimado, sino como projecto que debe relacionarse" (2010, p. 182)

${ }^{39}$ A noção de minoria e maioria estende-se para além de uma noção quantitativa. A minoria apresenta-se como "um subsistema ou fora do sistema" não importando se em termos de quantidade seja maior que a maioria. Esta, diferente daquela, "implica uma constante, de 
Teseu, o labirinto e seu nome: como Homi K. Bhabha poderia nos ajudar a compreender uma passagem de Moi, Tituba Sorcière..., de Maryse Condé?| 101

uma via para compreender os argumentos de John Índio que, antes de impelir Tituba a uma adoção da religião da comunidade de Salem, lhe apresenta a dissimulação de seus princípios como estratégia momentênea de sobrevivência, naquele contexto ali apresentado ${ }^{40}$. Para fins de leitura da passagem de Bhabha, as aspas em estão nos relembram, para além da mobilidade possível a estes sujeitos em-subalternidade (a diegese traz a situação objetiva da escravizção, assim como o racismo dela decorrente, ao longo de toda obra), a necessidade de questionar a naturalização da subalternidade, do que decorreria uma posição natural[izada]mente subalterna às personagens escravizadas e, tendo em vista a suposição de homogeneidade de nossos Outros, tal posição extendida a todas(os) sujeitas(os) negras(os), coeltiva e indistintamente.

O que é impressionante no "novo" internacionalismo é que o movimento do específico ao geral, do material ao metafórico, não é uma passagem suave de transição e transcendência. A "meia passagem" [middle passage] da cultura contemporânea, como no caso da própria escravidão, é um processo de deslocamento e disjunção que não totaliza a experiência (Idem, p. 26).

Por esse viés, se pode interpretar a busca imediata de uma dimensão coletiva às culturas negras (aquí, compreendidas no sentido de Hall (2004) ao propor a pregunta sobre o que se entende como cultura negra) como um sintoma da naturalização de subalternidade a sujeitas(os) negras(os) ou, em um sentido mais largo, a nossos Outros como aqueles portadores de ausência de Ser, de insuficiência de Sujeito: estes fora do domínio da subjetividade (negros são todos iguais), da cultura (negros como natureza, como paisagem), da nação (a África como país). Nesse sentido, não se pode falar em oposição entre valores culturais pois, no

expressão ou de conteúdo, como um metro padrão em relação o qual ela é avaliada (DELEUZE; GUATTARI, 2011, p. 55)."

${ }^{40}$ Nesta passagem, a percepção da provisoriedade na estratégia de John Índio nos evoca a noção de Desvio, em Édouard Glissant, em sua exigência de provisoriedade para enfrentar, de modo pontual, um conflito que se apresenta dinâmico e exige, por conseguinte, modos dinâmicos de resistência. Isso implica perceber a mobilidade não apenas nos deslocamentos do Sujeito (no sentido confeirdo por Spivak (2010), em sua critca a um pós-estruturalismo desde Michel Foucault e Gilles Deleuze) mas, igualmente, nos deslocamentos dos sujeitos escravizados em suas negociações culturais e politicas. 
interior do espaço das fronteiras dos protagonistas, existe uma dinamicidade, algo em produção, uma articulação que possibilita a invenção do "novo". Bhabha embasa essa dinâmica a partir da presença da autoridade: a resistência a essas regras de reconhecimento não significa uma "simples negação ou exclusão do 'conteúdo' de outra cultura"; todavia, o resultado dessa recusa, produzido como algo diferente, de acordo com Bhabha, é uma mutação, um híbrido. Portanto, o hibridismo

é o nome da reversão estratégica do processo de dominação pela recusa (ou seja, a produção de identidades discriminatórias que asseguram a identidade "pura" e original da autoridade). O hibridismo é a reavaliação do pressuposto da identidade colonial pela repetição de efeitos de identidade discriminatórios. Ele expõe a deformação e o deslocamento inerentes a todos os espaços de discriminação e dominação. Ele desestabiliza as demandas miméticas e narcísicas do poder colonial, mas confere novas implicações estratégicas de subversão que fazem o olhar do discriminado voltar-se para o olho do poder (...) (BHABHA, p. 185).

Para Bhabha, a produção de novos signos, nos espaços intersticiais, resultaria de efeitos discriminatórios do poder colonial no qual "o semântico parece prevalecer sobre o sintático, o significado sobre o significante" (p. 181). No romance de Condé, se pode apreciar esse processo dinâmico de ressignificação através dos diálogos e das passagens nos quais a memória, condição interstícia habitada por Tituba, oferece subsídios para indagar a autoridade e os significados da comunidade de Salem: “- Ai! O que está fazendo, feiticeira?/ Falava assim de brincadeira. De todo modo, fiquei espantada./ O que é uma feiticeira?/ Percebi que, em sua boca, a palavra estava manchada de desonra. Como isso? Como?" (CONDÉ, p. 28) $)^{41}$.

Tituba não entendia, inicialmente, o significado do termo feiticeira; percebe-se que, em suas indagações, há certa resistência à visibilidade imediata do regime de reconhecimento da autoridade

${ }^{41}$ Texto original: “- Aie! Qu'est-ce que tu fais là, sorciére?/ Il parlait ainsi par jeu./ Nèanmoins, cela m'assombrit./ Qu'est-ce qu'une sorcière?/ Je m'apercevais que dans as bouche, le mot était entaché d'opprobre. Comment cela? Comment?" ( p. 33) 
Teseu, o labirinto e seu nome: como Homi K. Bhabha poderia nos ajudar a compreender uma passagem de Moi, Tituba Sorcière..., de Maryse Condé?| 103

(BHABHA, p. 183). Nesses termos, destaca-se o sentido denotativo usual e a presença do termo que, ao ouvi-lo pela primeira vez, causou certo estranhamento, uma recusa que abrirá porta para um novo significado.

A faculdade de se comunicar com os invisiveis, manter uma ligação constante com os desaparecidos, de cuidar, de curar, não é uma graça superior da natureza, que inspira respeito, admiração e gratidão? Em consequência, a feiticeira, se se quer dar esse nome àquela que possui essa graça, não deveria ser tratada com desvelos e reverenciada em lugar de temida? (CONDÉ, p. 28, 29)

Mediante esse embate cultural entre significante e significado, na transformação do símbolo em signo, ocorre a produção de algo novo que não faz parte nem dos legados culturais ashantis nem dos da comunidade de Salem. Em meio a esse contexto, Tituba, personagem diaspórica e híbrida, vai se inserindo e se apropriando dos espaços até voltar ao seu lugar de origem e é nessa dinâmica extraterritorial e intercultural que a personagem, por motivos de sobrevivência, se vê obrigada a negociar entre uma e outra cultura. A partir desses deslocamentos espaciais, novos postos de significações são percebidos nos espaços intervalares entre as fronteiras em virtude "da supressão forçada da diferença cultural" (HALL, 2003, p. 59).

Analisar o hibridismo ${ }^{42}$ no romance de Condé significa reavaliar o pressuposto de uma identidade fixa através do processo de construção identitário de Tituba, elaborado sob o reconhecimento, por parte do Outro, de um modo de ser falso, deformado e redutor. Nesses termos, compreende-se que a noção de desvio na obra está vinculada às estratégias adotadas, pela personagem, buscando suportes a seus discurso e práticas e, assim, buscando compreender onde se situa a resistência frente a uma dominação que se mostra dissimulada (OLIVEIRA, ALVES, 2015). Esta

\footnotetext{
${ }^{42}$ Ressalta-se que parte da fortuna critica relativa ao tema antepõe os termos hibridismo e mestiçagem. Para Zilá Bernd, em "O elogio da crioulidade: o conceito de hibridação a partir dos autores francófonos do Caribe" (2004, p. 100), o problema da mestiçagem residiria em sua potencialidade de "camuflagem à manutenção de uma identidade calcada na homogeneidade, preocupada em integrar os grupos marginalizados, mas sempre de acordo com as concepções dominantes de nação". A escolha do vocábulo hibridação, segundo a autora, seria mais conveniente para abranger as diversas mesclas interculturais.
} 
hipótese permite uma maior percepção acerca da noção operatória de desvio e de práticas desviantes e, para tanto, toma-se como base Édouard Glissant (2010) que, em El Discurso Antillano, dedica algumas páginas acerca de tal concepção. Segundo as formulações do ensaísta antilhano, a noção de desvio está relacionada a não aceitação à dominação do Outro, uma resistência desassociada à ideia de fuga:

El Desvío no es un rechazo sistemático a ver. No, no es um modo de ceguera voluntaria ni una deliberada práctica de fuga ante las realidades. Más bien diríamos que suele ser el resultado de una marãna de negatividades asumidas como tales.[...] No hay desvío cuando la comunidad enfrenta a um enemigo conocido como tal (GLISSANT, 2010, p. 30).

Compreende-se o Desvio enquanto apelação de sujeitos situados num lugar onde a dominação se mostra oculta e por isso tem que se "buscar en otra parte el principio de la dominación" pois esta dominação "no es directamente visible" (GLISSANT, 2010, p. 30); ou seja, dado um contexto em que um Outro, conforme o ordenamento de uam sociedade escravocrata, estabelece suas condições, suas regras de reconhecimento - que segundo Bhabha (2013, p. 183), correspondem "aqueles textos sociais de inteligibilidade epistêmica, etnocêntrica, nacionalista” - nem sempre, na visão das personagens escravizadas, se sabe de fato quem as determina: "Que mundo era este, que tinha feito de mim uma escrava, uma órfã, uma pátria? Que mundo era este, que me separava dos meus? Que não falava minha língua, que não compartilhava minha religião, num país hostil e desagradável?" (CONDÉ, p. 70) ${ }^{43}$

Nesses termos, pela ótica da provisoriedade do Desvio, interpretase que, dentro do romance, os conhecimentos, apreendidos com uma nagô da costa, acerca da produção de poções feitas com ervas silvestres, são tomados por Tituba como estratégias de apropriações e vivências que permitem o enfrentamento de problemas insolúveis. Tituba se vale dos conhecimentos apreendidos com uma nagô da costa, curandeira famosa entre os escravizados, acerca da produção de poções com o auxílio de

\footnotetext{
${ }^{43}$ Texto original: "Quel était ce monde qui avait fait de moi une esclave, une orfheline, une paria? Quel était ce monde qui me séparait des miens? Qui m'obligeait à vivre parmi des gens qui ne parlaient pás mas langue, qui ne partageaient pás ma religion, dans um pays malgracieux, peu avenant?" (p. 81, 82)
} 
Teseu, o labirinto e seu nome: como Homi K. Bhabha poderia nos ajudar a compreender uma passagem de Moi, Tituba Sorcière..., de Maryse Condé?| 105

ervas cujos "frutos estorvantes" são capazes de viabilizar sua ação, já deliberada e premeditada ${ }^{44}$ : "Foi um pouco depois disso que me dei conta que estava grávida e decidi matar a criança" (CONDÉ, p. 70) ${ }^{45}$. Seu contexto a levou a buscar meios extremos de resistência como o infanticídio, levado a termo para livrá-lo de uma dominação dissimulada. Essa estratégia seria uma recusa ou negação em repor a mão de obra, o último recurso (GLISSANT, 2010, p. 30) para se evitar a escravização ante o julgo do poder.

Para uma escrava, a maternidade não é uma felicidade. Ela joga num mundo de servidão e de abjeção um pequeno inocente, a quem será impossível mudar o destino. Durante toda a minha infância, vi escravas assassinarem seus recémnascidos enfiando um longo espinho no ovo ainda gelatinoso da cabeça deles, cortando com uma faca envenenada o cordão umbilical ou ainda abandonando-os à noite num local frequentados por espíritos irritados. Durante toda a minha infância, ouvi as escravas trocarem receitas de poções, lavagens, injeções que esterilizavam para sempre as matrizes e as transformavam em túmulos alcatifados de sudários escarlates. (p. 71) ${ }^{46}$

A percepção de uma prática desviante ocasionada, intencionalmente, por meio do rompimento de uma gestação permitir-

\footnotetext{
${ }^{44}$ Seria conveniente citar, nesta análise, a elucidação trazida por Alcione Corrêa (2013), em que discorre sobre a apropriação e a significação da natureza local por parte dos sujeitos escravizados: no romance de Condé, Tituba que, alheia a esta flora local (pois era acostumada a manipular as plantas de Barbados, sua terra natal) teve de operar a ressignificação, naquele espaço, desse conhecimento adquirido no espaço de Boston.

${ }^{45}$ Texto original: "Ce fut peu après cela que je m'aperçus que je portais un enfant et que je décidai de le tuer." (p. 82)

46 Texto original: "Pour une esclave, la maternité n'est pas un bonheur. Elle revient à expulser dans un monde de servitude et d'abjection, un petit innocent dont il lui sera impossible de changer la destinée. Pendant toute mon enfance, j'avais vu des esclaves assassiner leurs nouveau-nés em plantant une longue épine dans l'oeuf encore gélatineux de leur tête, en sectionnant avec une lame empoisonnée leur ligament ombilical ou encore, en les abandonnant de nuit dans un lieu parcouru par des esprits irrités. Pendant toute mon enfance, j'vais entendu des esclaves échanger les recettes des potions, des lavements, des injections qui stérilisent à jamais les matrices et les transforment en tombeaux tapissés de suiares écarlates" (p. 83)
} 
nos-ia a compreensão do caráter de resistência de Tituba, enquanto mulhe negra escravizada, ante uma dominação dissimulada. Bhabha salienta que, a respeito dessa prática comum em mulheres negras escravizadas num contexto colonial, "esse ato trágico e íntimo de violência é executado como parte de uma luta para fazer recuar as fronteiras do mundo escravo"; sob tais condições, "o infanticídio era visto como ato contra o sistema e, pelo menos, reconhecia a posição legal da escrava na esfera pública" (2013, p. 43). Não obstante, essa prática, bem como a acepção do significado do termo feiticeira, fazem parte ambas do processo de construção identitária de Tituba.

\section{REFERENNCIAS}

ALVES, A. C. «Mon mom, je l'habite tout entier»: littérature-monde en français e seus lugares de enunciação. 208f. Tese (Doutorado) Universidade Federal do Rio Grande do Sul. Instituto Letras. Programa de Pós-Graduação em Letras, Porto Alegre, 2012.

- Teseu, o labirinto e o seu nome: conhecimento é resistência. Revista Caligrama, v. 18, p. 163-183, 2013.

. Desvio (Détour). In: BERND, Z. (Org.). Dicionário das mobilidades

culturais: percursos americanos. Porto Alegre: Literalis, 2010, p. 129-145.

ARROYO PIZARRO, Yolanda. Hablar de las Ancestras: hacia una nueva literatura insurgente de la afrodescendencia. In: Cruce: crítica sociocultural contemporánea. Disponivel em: <http://revistacruce.com/letras/item/1559-hablar-de-las-ancestras-haciauna-nueva-literatura-insurgente-de-la-afrodescendencia>. Último acesso em 24 de setembro de 2015, 11:27hs. . las Negras. Carolina (Puerto Rico): Boreales, 2012.

BHABHA, Homi K. O local da cultura. Tradução de Myriam Ávila, Eliana Lourenço de Lima Reis, Gláucia Renate Gonçalves. Belo Horizonte: Ed. da UFMG, 2013. 
Teseu, o labirinto e seu nome: como Homi K. Bhabha poderia nos ajudar a compreender uma passagem de Moi, Tituba Sorcière..., de Maryse Condé?| 107

CONDÉ, Maryse. Eu, Tituba, feiticeira...negra de Salem. Tradução de Angela Melim. Rio de Janeiro: Rocco, 1997.

CONDÉ, Maryse. Moi, Tituba, sorcière... Paris: Gallimard, 1986.

COSER, Stelamaris. Híbrido, hibridismo e hibridização. In: FIGUEIREDO, Eurídece (Org.). Conceitos de Literatura e Cultura. Niterói: EdUFF; Juiz de Fora: EdUFJF, 2012. p. 163-188.

DELEUZE, Gilles; GUATTARI, Félix. Mil Platôs: Capitalismo e esquizofrenia. Tradução de Ana Lúcia de Oliveira e Lúcia Cláudia Leão. São Paulo: Ed. 34, 1995.

FANTINI, Marli. Águas turvas, identidades quebradas: hibridismo, heterogeneidade, mestiçagem \& outras misturas. In: ABDALA JR., Benjamin (org.). Margens da cultura: mestiçagem, hibridismo $\mathfrak{E}$ outras misturas. São Paulo: Boitempo, 2004. p. 159-180.

GLISSANT, Édouard. El Discurso Antillano. Tradução de Aura Marina Boadas, Amélia Hernández e Lourdes Arencibia Rodríguez. Havana: Fondo Editorial Casa de las Américas, 2010.

. O mesmo e o diverso. In: BERND, Zilá (org). Antologia de textos fundadores do comparatismo literário interamericano. Disponível em: <http://www.ufrgs.br/cdrom/glissant/index.htm>. Último acesso em: 10 jun. 2016.

HALL, Stuart. A identidade cultural na pós-modernidade. Tradução de Tomaz Tadeu da Silva, Guaraciara Lopes Louro. Rio de Janeiro: DP\&A, 2003.

HANCIAU, Nubia. Entre-lugar. In: FIGUEIREDO, Eurídece (Org.). Conceitos de Literatura e Cultura. Niterói: EdUFF; Juiz de Fora: EdUFJF, 2012. p. 125-141.

KANOR, Fabienne. Humus. Paris: Gallimard, 2006 (Continents noirs).

. Sans titre. In: LE BRIS, Michel; ROUAUD, Jean (dirs.). Pour une littérature-monde. Paris: Gallimard, 2007, p. 237-242. 
LEENHARDT, Jacques. Fronteiras, fronteiras culturais e globalização. Trad. Sandra Jatahy Pesavento. In: MARTINS, Maria Helena (org.). Fronteiras culturais - Brasil, Uruguai, Argentina. Cotia, São Paulo: Ateliê Editorial, 2002, p. 27-34.

OLIVEIRA, Jonata Alisson Ribeiro de; ALVES, Alcione Correa. Identidade, ressignificação e resistência. In: DE OLIVEIRA, Humberto Luiz Lima; ABOMO-MAURIN, Marie-Rose; MBARGA, Christian (Org.). Terres d'exil, terres d'accueil: identités. Paris: L'Harmattan, 2015, v. 1, p. 71 81.

SPIVAK, Gayatri Chakravorty. Pode o subalterno falar? Tradução de Sandra Regina Goulart Almeida, Marcos Pereira Feitosa, André Pereira Feitosa. Belo Horizonte: Ed. da UFMG, 2010.

Recebido em: 30/06/2016

Aceito em: 16/08/2016 